\title{
Unveiling an intimate affair
}

\author{
Pierre Voisine, MD, FRCSC
}

\author{
From the Department of Surgery, Université Laval, Québec City, Québec, Canada; and the Division of Cardiac \\ Surgery, Department of Cardiology, Institut Universitaire de Cardiologie et de Pneumologie de Québec \\ (IUCPQ), Québec City, Québec, Canada. \\ Disclosures: Author has nothing to disclose with regard to commercial support. \\ Received for publication Oct 31, 2017; accepted for publication Nov 8, 2017; available ahead of print Jan 2, 2018. \\ Address for reprints: Pierre Voisine, MD, FRCSC, 2725 Chemin Ste-Foy, Ville de Québec, Québec G1V 4G5, \\ Canada (E-mail: Pierre.voisine@chg.ulaval.ca). \\ J Thorac Cardiovasc Surg 2018;156:641-2 \\ $0022-5223 / \$ 36.00$ \\ Copyright (C) 2017 by The American Association for Thoracic Surgery \\ https://doi.org/10.1016/j.jtcvs.2017.11.021
}

Teaching operative techniques in cardiac surgery remains a constantly evolving challenge. Patients undergo operations with complexities that leave little room for the extended crossclamp times that the hands of an unexperienced trainee often require. Technical errors are difficult to rectify in this fragile population, and surgeons walk on thinner ice than ever when providing essential hands-on learning experiences to their apprentices. This is especially true in situations such as mitral valve surgery, where exposure of target anatomic structures is restricted, which not only prevents full appreciation of procedural subtleties by learners but also renders teachers' adequate supervision difficult. Mitral surgery is an intimate affair between valve and operator.

To circumvent these limitations, live animal models have traditionally been used; however, cost and ethical issues have led to a fall in their presence in US medical schools curricula, from $90 \%$ in 1987 to $32 \%$ in 2001 , and their complete removal in $2016 .{ }^{1}$ Along with this attrition, simulation-based learning never ceased growing and has become part of elaborate and structured programs in cardiac surgery. ${ }^{2,3}$ Although simulation provides opportunities to practice the mechanics of a procedure, however, it often associates with an unrealistic context where the feeling of working with live tissue is not reproduced.

Acquiring the skills for off-pump transventricular mitral valve repair is particularly difficult in this regard. New adopters of the technique usually are experienced surgeons, familiar with direct-vision or video-assisted manipulation of tissue, who need to learn to rely on transesophageal echocardiographic guidance. The translation of echocardiographically guidance into visually interpretable images is obviously not possible in any live model, and no traditional simulator can provide the real-feeling experience that could adequately prepare for this type of procedure in human patients. In their article in the January 2018 issue of the Journal, Leopaldi and colleagues ${ }^{4}$ describe a perfect combination

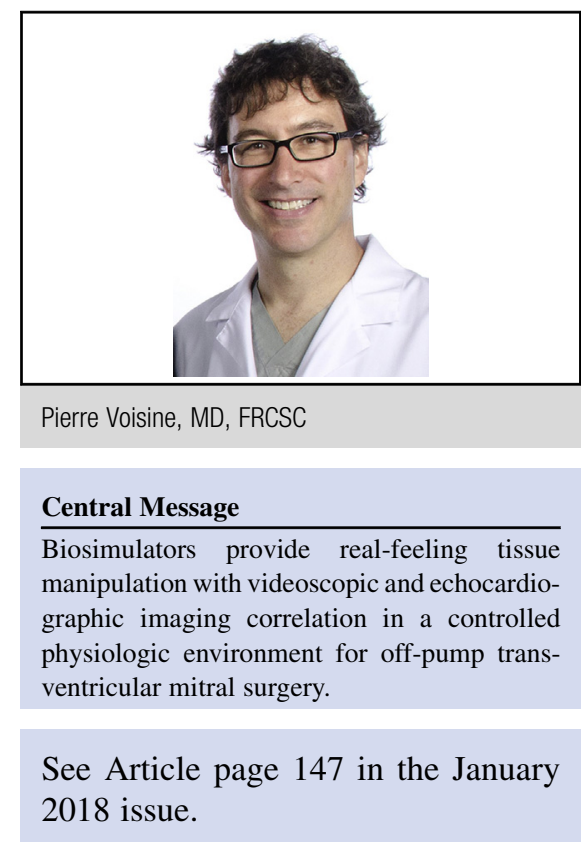

of biologic organ and mechanical technology into a hybrid "biosimulator" that succeeds in these aspects. This apparatus combines the use of an ex vivo beating heart, with the feeling of real tissue, set up in a controlled environment in which the physiologic conditions of a regurgitant mitral valve can be recreated. Assimilation by dual echocardiographic and videoscopic imaging provides users with an invaluable opportunity to entrench new experiences into consolidated and long-acquired skills. The correlation of this input with the hemodynamic impact of procedural correction of the pathologic process gives learners immediate feedback on their performance, which through practice can make them virtual experts by the time they undertake their first real-life case.

This equipment certainly fills a need as a training tool for a specific procedure that takes surgeons out of their "direct vision" comfort zone. It helps in teaching the technique to and evaluating the learning curve of apprentices, assessing preparedness and competency. It is a perfect example of "deliberate practice," an educational technique aimed at improving performance by intense training and preparation through repetition, assessment, and feedback in a less stressful environment devoid of time restriction or patient safety concerns. With the continuous development of minimally invasive off-pump surgical approaches, the possibilities for the use of this biosimulator in teaching, research, and technology development are simply endless. 


\section{References}

1. Simkin DJ, Greene JA, Jung J, Sacks BC, Fessler HE. The death of animals in med ical school. N Engl J Med. 2017;376:713-5.

2. Moorjani N, Lewis M, Shah R, Barnard S, Graham T, Rathinam S. Implementation of a novel portfolio of structures, curriculum-aligned, simulation-based, cardiothoracic surgery training course: evolving the delivery of surgical education. $J$ Thorac Cardiovasc Surg. 2017;154:2009-16.
3. Baker CJ, Sinha R, Sullivan ME. Development of a cardiac surgery simulation curriculum: from needs assessment results to practical implementation. J Thorac Cardiovasc Surg. 2012;144:7-16.

4. Leopaldi AM, Wrobel K, Speziali G, van Tujil S, Drasutiene A, Chitwood R Jr. The dynamic cardiac biosimulator: a method for training physicians in beating-heart mitral valve repair procedures. J Thorac Cardiovasc Surg. 2018; $155: 147-55$. 